See Article page XXX.

\section{Commentary: Earlier warning for pulmonary complications: It's never too soon to take action}

\author{
Arsalan Amin, MD, ${ }^{\mathrm{a}}$ and Subhasis Chatterjee, $\mathrm{MD}^{\mathrm{a}, \mathrm{b}, \mathrm{c}}$
}

In 2016, Edwards and colleagues ${ }^{1}$ published an illuminating report on failure to rescue in more than 600,000 patients in the Society of Thoracic Surgeons National Database who had undergone coronary artery bypass grafting. Analyzing major complications (ie, stroke, reoperation, renal failure, and prolonged ventilation), the authors found that any 1 of those complications was reasonably tolerated, with a $5 \%$ mortality rate; however, having 2 complications increased mortality to $20 \%$ to $30 \%$. Moreover, differences in postcomplication mortality were not explained by any complication's frequency; rather, higher rates of failure to rescue at higher-mortality surgical centers were more explanatory. This suggests that prompt recognition and timely management were responsible for much of the mortality differences.

A Cardiothoracic Surgery Network analysis of 5158 adult cardiac surgery patients found a $2.4 \%$ incidence of pneumonia that was associated with a 9-fold increase in mortality; major risk factors included mechanical ventilation longer than 48 hours, nasogastric tubes, and transfusions. ${ }^{2}$ Prophylactic second-generation cephalosporins and platelet transfusion were protective. These complications have a major influence on costs, adding approximately $\$ 38,000$ per case. In a systematic review and meta-analysis of 11

\footnotetext{
From the Divisions of ${ }^{\mathrm{a} C}$ ardiothoracic Surgery and ${ }^{\mathrm{b}}$ General Surgery, Michael E. DeBakey Department of Surgery, Baylor College of Medicine, Houston, Tex; and ${ }^{\mathrm{c}}$ Department of Cardiovascular Surgery, Texas Heart Institute, Houston, Tex.

Disclosures: Dr Chatterjee has served on advisory boards for Edwards Lifesciences, Baxter, and La Jolla Pharmaceutical Company. Dr Amin reported no conflicts of interest.

The Journal policy requires editors and reviewers to disclose conflicts of interest and to decline handling or reviewing manuscripts for which they may have a conflict of interest. The editors and reviewers of this article have no conflicts of interest.

Received for publication Sept 24, 2021; revisions received Sept 24, 2021; accepted for publication Sept 24, 2021.

Address for reprints: Subhasis Chatterjee, MD, Division of Cardiothoracic Surgery, Michael E. DeBakey Department of Surgery, Baylor College of Medicine, One Baylor Plaza, MS: BCM 390, Houston, TX 77030-3411 (E-mail: subhasis. chatterjee@bcm.edu).

J Thorac Cardiovasc Surg 2021; $\mathbf{\square}: 1-3$

$0022-5223 / \$ 36.00$

Copyright (c) 2021 by The American Association for Thoracic Surgery

https://doi.org/10.1016/j.jtcvs.2021.09.039
}

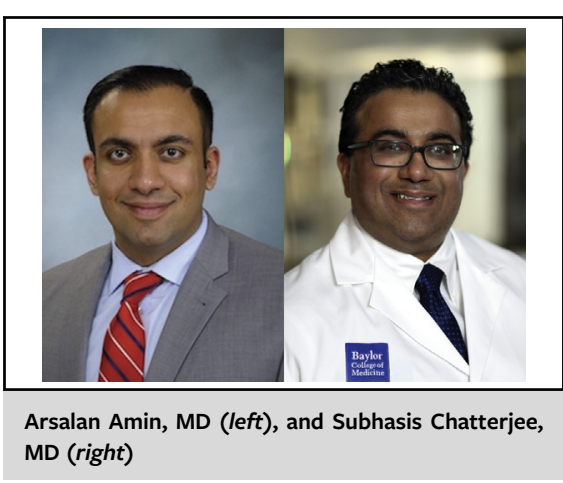

\section{CENTRAL MESSAGE \\ Earlier identification of postop- erative pulmonary complications after cardiac surgery may allow for earlier intervention.}

studies and 10,078 patients, $\mathrm{He}$ and colleagues ${ }^{3}$ found that $35 \%$ of patients mechanically ventilated longer than 48 hours developed pneumonia. The significance of postoperative pulmonary complications after cardiac surgery is readily apparent.

Khanna and colleagues ${ }^{4}$ from the Cleveland Clinic report results from a high-quality, statistically sound study with a robust dataset (a derivation cohort of 17,433 patients and a validation cohort of 12,843 patients), and they have provided a nomogram to predict the development of postoperative pulmonary complications (PPCs) (ie, pneumonia, reintubation, or the need for mechanical ventilation beyond 48 hours). Overall, almost $10 \%$ of patients developed 1 or more PPC $(7.8 \%$ experienced 1 PPC, $1.6 \%$ experienced 2 , and $0.2 \%$ had all 3 ); mortality in this group was $11.4 \%$. The mortality rate was $16.2 \%$ for patients with pneumonia, $11.5 \%$ in reintubated patients, and $11.4 \%$ in patients requiring $>48$ hours of mechanical ventilation. In contrast, the mortality rate for patients who did not develop PPCs was only $0.4 \%$. Targeted efforts to identify patients at higher risk for developing complications may help to reduce the incidence of PPCs.

Khanna and colleagues ${ }^{4}$ model for predicting PPCs includes 25 independent variables: 13 preoperative, 10 intraoperative, and 2 immediately postoperative. This model showed very good discrimination $(C$ statistic, 0.87$)$ and calibration (Brier score, 0.07). In comparison, 1 model using artificial neural networks and preoperative variables produced an area under the curve of 0.62 to 0.72 for predicting reintubation and prolonged ventilation after 
cardiac surgery. ${ }^{5}$ Of note, a scoring system with a cumbersome number of variables might be easy to use with a retrospective database containing already-entered values but would have less clinical utility at the bedside.

The challenge with risk-scoring systems is that 1 based only on preoperative variables will be less accurate; nonetheless, early analysis could provide an opportunity to intervene preoperatively or intraoperatively to reduce PPC incidence or, in prohibitively high-risk cases, to consider alternative, less-invasive procedures (or no surgery at all). On the other hand, introducing intraoperative variables improves the accuracy of the risk score but affords fewer opportunities for intervention before surgery. By including 2 variables that are determined on arrival to the intensive care unit (inhaled nitric oxide/prostaglandin E2 and higher plateau pressures), Khanna and colleagues ${ }^{4}$ model further increases prediction accuracy, even while PPCs are actually occurring.

In comparing Khanna and colleagues ${ }^{4}$ model with other recent cardiac surgery models developed through multivariable analysis, we noted 3 common major risk factors: age, cardiopulmonary bypass time, and transfusions. Specifically, Kilic and colleagues ${ }^{6}$ analyzed 6222 patients undergoing cardiac surgery and found a $4.5 \%$ incidence of pneumonia. The authors developed a scoring system that included 6 risk factors (age, chronic lung disease, peripheral vascular disease, cardiopulmonary bypass time, intraoperative red blood cell transfusion, and preoperative/intraoperative intra-aortic balloon pump use) with modest predictive accuracy ( $C$ statistic, 0.76 ). Allou and colleagues ${ }^{7}$ analyzed 5582 patients with a $3 \%$ overall pneumonia rate and developed a scoring system that included age, chronic obstructive pulmonary disease, left ventricular ejection fraction, red blood cell transfusion, and cardiopulmonary bypass time. Finally, Wang and colleagues ${ }^{8}$ analyzed 5323 patients with a $10 \%$ pneumonia incidence and developed a scoring system comprising 13 risk factors, including age, transfusion, and cardiopulmonary bypass duration, among other preoperative variables $(C$ statistic, 0.80$)$.

What, then, is one to do with patients identified as having higher risk for developing pulmonary complications, to reduce that risk or minimize adverse consequences? What risk factors are modifiable? It is likely that, aside from a prohibitively high risk for respiratory failure from severe underlying lung disease, most patients will proceed with surgery. What specific interventions (if any) should be introduced, beyond standard lung protective ventilation and other fundamentals of ventilator management and postoperative respiratory care? Could high-risk patients benefit from preoperative pulmonary rehabilitation, ${ }^{9}$ avoidance of after-hours extubation, increased duration of perioperative antibiotics, toilet bronchoscopy before extubation, and progression from extubation to noninvasive modes of ventilation or high-flow nasal oxygen in a protocolized manner? $?^{10,11}$ Indeed, evidence-based strategies such as chlorhexidine oral care, head-of-bed elevation, pulmonary hygiene, and postoperative protocols encouraging pulmonary toilet and mobilization are necessary.

Moreover, there may be opportunities to reduce the risk of PPCs from intraoperative strategies. Blood conservation efforts should be encouraged, because the transfusion of even 1 to $2 \mathrm{U}$ packed red blood cells doubles the risk for pneumonia. ${ }^{12}$ Moreover, intraoperative ventilation management may reduce the likelihood of PPC development; 1 analysis of 4694 cardiac surgical procedures found that an intraoperative lung-protective ventilation bundle was independently associated with fewer pulmonary complications. ${ }^{13}$ Increasingly in the acute respiratory distress syndrome literature, the concept of driving pressure expressed as the ratio of tidal volume to static lung compliance (or at the bedside as plateau pressure minus positive end-expiratory pressure) has been identified as the central variable for mechanical ventilation optimization. ${ }^{14}$ By sensitivity analysis, a modified intraoperative driving pressure $<16 \mathrm{~cm} \mathrm{H}_{2} \mathrm{O}$ was most protective, compared with intraoperative vital volume $<8 \mathrm{~mL} / \mathrm{kg}$ of predicted body weight or positive end-expiratory pressure $\geq 5 \mathrm{~cm} \mathrm{H}_{2} \mathrm{O} .{ }^{13}$ This highlights a potential role for intraoperative ventilation optimization that can be systematically implemented.

Reducing the incidence and severity of pulmonary complications after cardiac surgery requires preoperative, intraoperative, and postoperative strategies. Even a $1 \%$ absolute reduction in the incidence of pulmonary complications would measurably decrease mortality rates and cost savings. Achieving such a reduction will require multidisciplinary collaboration to identify higher-risk patients.

\section{References}

1. Edwards FH, Ferraris VA, Kurlansky PA, Lobdell KW, He X, O'Brien SM, et al. Failure to rescue rates after coronary artery bypass grafting: an analysis from the Society of Thoracic Surgeons adult cardiac surgery database. Ann Thorac Surg. 2016;102:458-64.

2. Ailawadi G, Chang HL, O'Gara PT, O'Sullivan K, Woo YJ, DeRose JJ Jr, et al. Pneumonia after cardiac surgery: experience of the National Institutes of Health/ Canadian Institutes of Health research cardiothoracic surgical trials network. $J$ Thorac Cardiovasc Surg. 2017;153:1384-91.e3.

3. He S, Chen B, Li W, Yan J, Chen L, Wang X, et al. Ventilator-associated pneumonia after cardiac surgery: a meta-analysis and systematic review. J Thorac Cardiovasc Surg. 2014;148:3148-55.e5.

4. Khanna AK, Kelava M, Ahuja S, Makarova N, Liang C, Tanner D, et al. A nomogram to predict postoperative pulmonary complications after cardiothoracic surgery. J Thorac Cardiovasc Surg. 2021. XX:XX-X.

5. Mendes RG, de Souza CR, Machado MN, Correa PR, Di Thommazo-Luporini L, Arena $\mathrm{R}$, et al. Predicting reintubation, prolonged mechanical ventilation and death in post-coronary artery bypass graft surgery: a comparison between artificial neural networks and logistic regression models. Arch Med Sci. 2015;11: 756-63.

6. Kilic A, Ohkuma R, Grimm JC, Magruder JT, Sussman M, Schneider EB, et al. A novel score to estimate the risk of pneumonia after cardiac surgery. J Thorac Cardiovasc Surg. 2016;151:1415-20.

7. Allou N, Bronchard R, Guglielminotti J, Dilly MP, Provenchere S, Lucet JC, et al. Risk factors for postoperative pneumonia after cardiac surgery and development of a preoperative risk score. Crit Care Med. 2014;42:1150-6. 
8. Wang D, Huang X, Wang H, Le S, Yang H, Wang F, et al. Risk factors for postoperative pneumonia after cardiac surgery: a prediction model. J Thorac Dis. 2021;13:2351-62.

9. Shakouri SK, Salekzamani Y, Taghizadieh A, Sabbagh-Jadid H, Soleymani J, Sahebi L, et al. Effect of respiratory rehabilitation before open cardiac surgery on respiratory function: a randomized clinical trial. J Cardiovasc Thorac Res. 2015;7:13-7.

10. Melton N, Lazar JF, Childers WK, Anderson D, Jaik NP, Loran DB, et al. Preventing respiratory failure after cardiac surgery using post-extubation bilevel positive airway pressure therapy. Cureus. 2019;11:e4236.

11. Stéphan F, Barrucand B, Petit P, Rézaiguia-Delclaux S, Médard A, Delannoy B, et al. High-flow nasal oxygen vs noninvasive positive airway pressure in hypoxemic patients after cardiothoracic surgery: a randomized clinical trial JAMA. 2015;313:2331-9.

12. Likosky DS, Paone G, Zhang M, Rogers MA, Harrington SD, Theurer PF, et al Red blood cell transfusions impact pneumonia rates after coronary artery bypass grafting. Ann Thorac Surg. 2015;100:794-800.

13. Mathis MR, Duggal NM, Likosky DS, Haft JW, Douville NJ, Vaughn MT, et al. Intraoperative mechanical ventilation and postoperative pulmonary complications after cardiac surgery. Anesthesiology. 2019;131: 1046-62.

14. Amato MB, Meade MO, Slutsky AS, Brochard L, Costa EL, Schoenfeld DA, et al. Driving pressure and survival in the acute respiratory distress syndrome. N Engl J Med. 2015;372:747-55. 